\title{
Carlos gaspe.
}

Egresado como licenciado de la Universidad de Carabobo en Relaciones Industriales.

\section{Carlos Palencia.}

Licenciado en Administración Comercial, Universidad de Carabobo, Venezuela.

\section{Enmari Molina.}

Licenciada en Contaduría Pública de la Universidad de Carabobo, Venezuela.

\section{fernando Löpez.}

Licenciado en Relaciones Industriales de la Universidad de Carabobo, Venezuela.

\section{gesús Arciniegas.}

Licenciado en Administración Comercial egresado de la Universidad de Carabobo, Venezuela.

\section{Kenia Escalona.}

Egresado de la Universidad de Carabobo como Contadora Pública en la Universidad de Carabobo, Venezuela. 


\section{Curriculo de Autores}

\section{Leunam Montaner.}

Licenciado en Contaduría Pública egresado de la Universidad de Carabobo, Venezuela.

\section{Maria Patricia Paz.}

Licenciada en Contaduría Pública de la Universidad de Carabobo, Venezuela.

\section{Marianny Viloria.}

Licenciada en Contaduría Pública de Universidad de Carabobo, Venezuela.

\section{Sandra Barón.}

Licenciada en Contaduría Pública de la Universidad de Carabobo, Venezuela.

\section{Soleini Moya.}

Egresado de la Universidad de Carabobo en Relaciones Industriales Universidad de Carabobo, Venezuela.

\section{Susana fermin.}

Licenciada en Contaduría Pública de la Universidad de Carabobo, Venezuela. 